\title{
Effects of temperature and strain rate on the mechanical properties of T91 material tested in liquid lead bismuth eutectic
}

\author{
J. Van den Bosch *, D. Sapundjiev, A. Almazouzi \\ SCK•CEN (Belgian Nuclear Research Centre), Boeretang 200, B-2400 Mol, Belgium
}

\begin{abstract}
The effects of temperature and strain rate on the susceptibility of one of the most promising candidate materials for cladding and high temperature components for ADS, Ferritic/Martensitic steel (T91), to liquid metal embrittlement have been investigated in the temperature interval $150-450^{\circ} \mathrm{C}$, at strain rates between $1 \times 10^{-3} \mathrm{~s}^{-1}$ and $1 \times 10^{-6} \mathrm{~s}^{-1}$. The effect of the liquid lead bismuth eutectic has been evaluated by comparison between tests in the liquid metal and in Ar with 5\% $\mathrm{H}_{2}$. Although the untreated T91 material did not undergo liquid metal embrittlement and there was no apparent change in trends of the tensile properties as function of temperature or strain rate due to the liquid metal, the pre-exposed T91, which was exposed to oxygen poor LBE at $450{ }^{\circ} \mathrm{C}$ for $4000 \mathrm{~h}$ and tested at $450{ }^{\circ} \mathrm{C}$ did show a decrease in total elongation. The total elongation of the untreated T91 specimens in liquid lead bismuth and in $\mathrm{H}_{2} /$ Ar-gas mixture followed the same dependence on the temperature up to $245^{\circ} \mathrm{C}$. At temperatures above $375^{\circ} \mathrm{C}$ no results are available from testing in controlled gas environment however reference data measured on the same batch of steel in air are used for comparison. Varying the strain rate did not cause any deterioration in the tensile properties of the material in liquid metal compared to those in gas atmosphere. The results are discussed in terms of self-healing mechanism and crack initiation processes.
\end{abstract}

(c) 2006 Elsevier B.V. All rights reserved.

\section{Introduction}

In recent years the interest of the nuclear research sector towards liquid lead and lead bismuth eutectic arose due to their selection as working fluids for advanced nuclear applications such as GEN IV, ADS and fusion [1,2]. One example is the develop-

\footnotetext{
* Corresponding author. Tel.: +32 14 333191; fax: +32 14 321216.

E-mail address: joris.van.den.bosch@sckcen.be (J. Van den Bosch).
}

ment of the accelerator driven system (ADS) MYRRHA at the Belgian Nuclear Research Centre, $\mathrm{SCK} \bullet \mathrm{CEN}$. This transmutation reactor is designed to have liquid lead bismuth eutectic (LBE) as spallation target material as well as for primary coolant [3].

Although the risk of embrittlement of materials exposed to liquid metals has been recognized for many years, its prediction remains problematic due to the limited knowledge of the mechanisms involved in the phenomenon. Generally, when solid metals are exposed to liquid metals and stress is applied, they may undergo abrupt brittle failure known as liquid metal embrittlement (LME). It is 
characterized by a premature brittle failure of an otherwise ductile material when placed in contact with specific liquid metal for the material under stress. LME is of prime interest because of the risk of damage wherever the handling of liquid metals is required. The phenomenon depends on many parameters (intensive and extensive) like metallurgical state, surface state, composition, solubility, temperature, strain rate, stress, etc. [4-6]. Temperature and strain rate are of extreme importance and will directly affect the severity of embrittlement of a given liquid metal/solid metal couple. According to the existing understanding of the phenomena of LME, the latter is severest at temperatures close to the melting point of the coolant metal. At higher temperatures, the phenomena of LME occurs with the same severity but it decreases until it disappears, so forming a temperature interval within which the material is susceptible to LME, known as ductility trough [7]. The extend of this interval of temperatures where the strain to rupture is largely reduced is constant for a given strain rate and its high temperature end decreases with decreasing strain rate. At a sufficiently low strain rate the occurrence of LME may disappear. When the test conditions are inside the ductility trough the tensile behaviour of the material is expected to change significantly under influence of the liquid metal. Two possible trends are described in the literature: (i) Westwood et al. [8] claim that the stress-strain behaviour of the solid metal is the same as in the unwetted condition until premature fracture occurs; while (ii) Popovich et al. [9] declare that there is an initial promotion of plastic flow and consequently a different plastic behaviour of the metal in presence of liquid metal before rupture. In both cases however, the elastic domain is unchanged in presence of liquid metal.

The ferritic-martensitic steel T91 has been selected as a candidate structural material for the high temperature parts of the ADS such as the sub-critical core which will be subjected to high irradiation doses. This selection is based on previous experience (steam generators, etc.) and the good swelling resistance of the material under irradiation. It is necessary for a future safe exploitation of an ADS to know the temperature range of a possible ductility trough due to LME as a function of strain rate so that any possible failure of the installation caused by LME can be avoided. Recently, several European groups, within both the FP5-MEGAPIE-TEST project [10] and the FP6-project EURO-
TRANS [11] have launched studies to assess the compatibility of the selected steel with LBE. Although some peculiar experiments have shown that liquid lead alloys may reduce the performance of T91 in terms of total elongation [12-15], T91 does not show liquid metal embrittlement by LBE under all conditions $[16,17]$. This paper describes a systematic study of T91 behaviour when subjected to LBE with controlled chemistry and well defined testing conditions.

\section{Experimental}

The tests were carried out using Liquid Metal Embrittlement Testing Station 1 (LIMETS 1) which was especially designed for testing in liquid lead bismuth environment. The machine is based on the three vessel concept, e.g. melting tank, dump tank and autoclave (see Fig. 1). The LBE material was delivered by Hetzel Metalle $\mathrm{GmbH}$, Germany with a composition of $55.2 \mathrm{wt} \% \mathrm{Bi}(4 \mathrm{~N})$ and $44.8 \mathrm{~Pb}$ (3N8), $2 \mathrm{mg} / \mathrm{g} \mathrm{Cr}$ and less than $1 \mathrm{mg} / \mathrm{g} \mathrm{Ni}$. The ingots were molten in the melting tank and transferred to the dump tank in the liquid state while leaving the slag layer in the melting tank thus avoiding contamination of the system. Inside the dump tank the LBE was stored and preconditioned before every test. The preconditioning was performed by bubbling argon gas or a mixture of 5\% hydrogen and $95 \%$ argon through the liquid metal at a well defined temperature. The tensile tests were performed using a $10 \mathrm{kN}$ machine. The samples were tested in the autoclave which was filled with 21 of preconditioned liquid metal after evacuating to a primary vacuum and filling with a hydrogen and argon gas mixture. This design allows to achieve clean LBE with a predefined and controlled oxygen concentration.

Small size cylindrical tensile samples were used with a total length of $27 \mathrm{~mm}$, a gauge length of $12 \mathrm{~mm}$ and a diameter of $2.4 \mathrm{~mm}$ (see Fig. 2(A)). These samples were manufactured in $\mathrm{L}$ orientation (rolling direction) with a lathe machine and did not undergo any other surface treatment. Prior to testing the samples were degreased by ultrasonic cleaning in methanol and dried in air. The samples were measured using one of two methods: a sliding calliper as shown in Fig. 2(A) or a digital profile projector (type Mutitoyo PJ300). Fig. 2(B) shows a SEM image of the sample surface. The cutting lines resulted from machining are clearly visible and it is obvious that the sample roughness is strongly influenced by the machining conditions. 


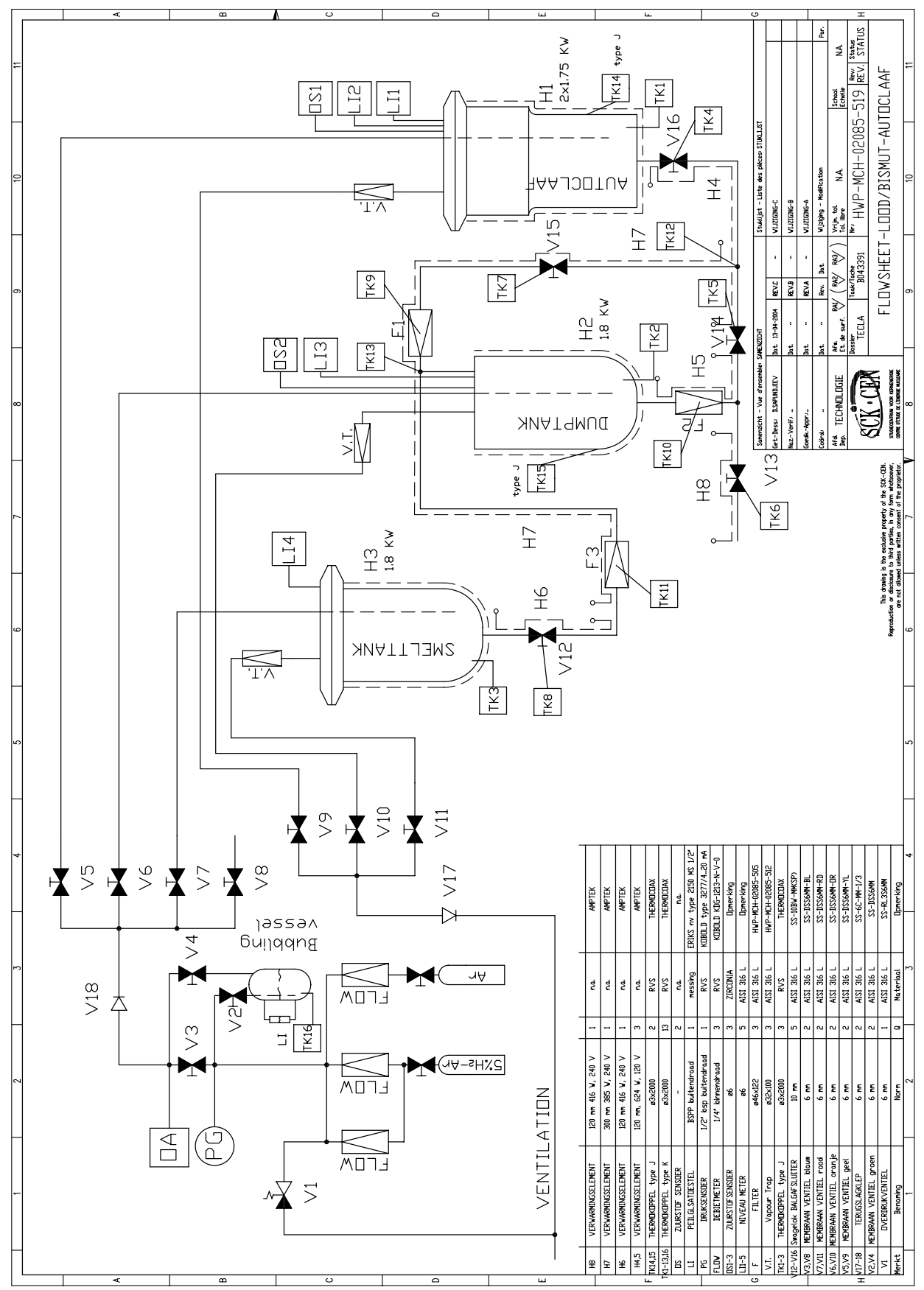




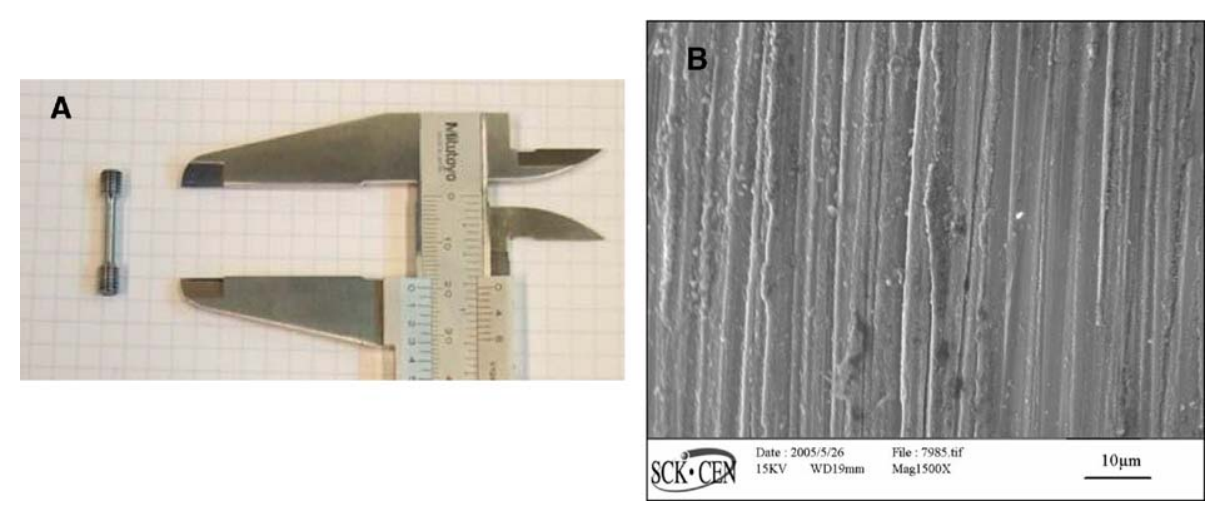

Fig. 2. (A) photograph of the small size cylindrical tensile specimen with the sliding calliper; (B) SEM-image of the machined sample surface.

Table 1

Chemical composition of the tested T91 material, wt $\%$

\begin{tabular}{llllllllllllllll}
\hline Material & $\mathrm{Fe}$ & $\mathrm{Cr}$ & $\mathrm{Ni}$ & $\mathrm{Mo}$ & $\mathrm{Mn}$ & $\mathrm{V}$ & $\mathrm{Nb}$ & $\mathrm{S}$ & $\mathrm{Si}$ & $\mathrm{N}$ & $\mathrm{C}$ & $\mathrm{P}$ & $\mathrm{B}$ \\
\hline T91 & Balance & 8.3 & 0.13 & 0.95 & 0.4 & 0.2 & 0.08 & - & 0.4 & 0.02 & 0.11 & - & - \\
\hline
\end{tabular}

The chemical composition of the T91 steel is given in Table 1. The material was supplied by Ugine, France (heat 36224) and was normalized at $1040{ }^{\circ} \mathrm{C}$ for $60 \mathrm{~min}$ and tempered at $760^{\circ} \mathrm{C}$ for $60 \mathrm{~min}$.

Tensile tests were performed to asses the susceptibility of T91 to liquid LBE embrittlement. The influence of strain rate was examined at two different temperatures $\left(245^{\circ} \mathrm{C}\right.$ and $\left.450{ }^{\circ} \mathrm{C}\right)$ by varying the strain rate between $1 \times 10^{-6} \mathrm{~s}^{-1}$ and $1 \times 10^{-3} \mathrm{~s}^{-1}$. The effect of temperature was characterized by testing at temperatures between $150^{\circ} \mathrm{C}$ and $450{ }^{\circ} \mathrm{C}$ at a constant strain rate of $5 \times 10^{-5} \mathrm{~s}^{-1}$. The influence of the liquid metal on the mechanical properties was determined by comparison with tensile tests performed using the same machine but in controlled gas environment. The results were compared to previous tensile tests performed in gas environment by different labs whithin the European FP5 Spire program on the same batch of T91 [18-22]. The susceptibility to environmentally induced cracking was evaluated by comparing the ratios of the strain to failure in liquid LBE and in controlled environment according to ASTM G 129-95 standard.

\section{Results and discussion}

In order to examine the effect of temperature on the susceptibility of T91 to liquid metal embrittle- ment a constant strain rate of $5 \times 10^{-5} \mathrm{~s}^{-1}$ was applied. This strain rate was chosen as an optimum between practical and physical considerations. For physical reasons it was best to have a slow strain rate to obtain wetting of fresh metal surface that appears by breaking the oxide layer on the sample surface and allowing the penetration of LBE. On the other hand from a practical point of view it is desirable to have a strain rate which results in the optimal use of the testing setup under controlled conditions (no oxygen concentration drift, no temperature shift, etc.). Taking into account the time needed for attaching the sample, heating, settling of temperature, testing and cooling a strain rate of $5 \times 10^{-5} \mathrm{~s}^{-1}$ made it possible to perform tests under well defined and controlled conditions. The tensile tests were performed in lead bismuth eutectic at temperatures between $150{ }^{\circ} \mathrm{C}$ and $450{ }^{\circ} \mathrm{C}$. To asses the possible occurrence of $\mathrm{LME}$, the results of the tests in LBE are compared with previous tensile tests performed in gas environment by different labs [18-22]. These tests were done within the European FP5 programme Spire and were all on the same batch of T91 as the one we tested in LBE. The equations of the curves fitted to the tensile results in gas environment between -150 and $550{ }^{\circ} \mathrm{C}$ are given in Table 2. To verify the fitted curves four tests were performed at temperatures between 100 and $250{ }^{\circ} \mathrm{C}$ in argon with $5 \%$ hydrogen gas environment using the same machine as for the tests in LBE. 
Table 2

Equations of tensile properties as function of temperature resulting from fitting to previous tensile tests in gas environment [18-22]

\begin{tabular}{llll}
\hline$\sigma_{0,2}$ & $\sigma_{\mathrm{UTS}}$ & $\varepsilon_{\text {total }}$ & $\varepsilon_{\text {unif }}$ \\
\hline $8 \times 10^{-10} T^{4}-3 \times 10^{-6} T^{3}$ & $-6 \times 10^{-9} T^{4}+3 \times 10^{-6} T^{3}$ & $7 \times 10^{-10} T^{3}+4 \times 10^{-8} T^{2}$ & $-8 \times 10^{-10} T^{3}+6 \times 10^{-7} T^{2}$ \\
$+0.0016 T^{2}-0.4878 T+536.1$ & $+0.0007 T^{2}-0.6782 T+693.09$ & $-0.0003 T+0.236$ & $-0.0002 T+0.0892$ \\
\hline
\end{tabular}

Fig. 3 shows the strength and ductility properties of the T91 material tested in liquid LBE and in hydrogen and argon gas mixture environments compared to the fitted curves from previous tests in gas environment as a function of temperature using a constant strain rate of $5 \times 10^{-5} \mathrm{~s}^{-1}$. The full symbols in the curves represent data obtained from tensile testing in liquid LBE whereas the empty ones are of the tests performed in the controlled gas environment. The yield strength, $\sigma_{0.2}$ and the ultimate ten-
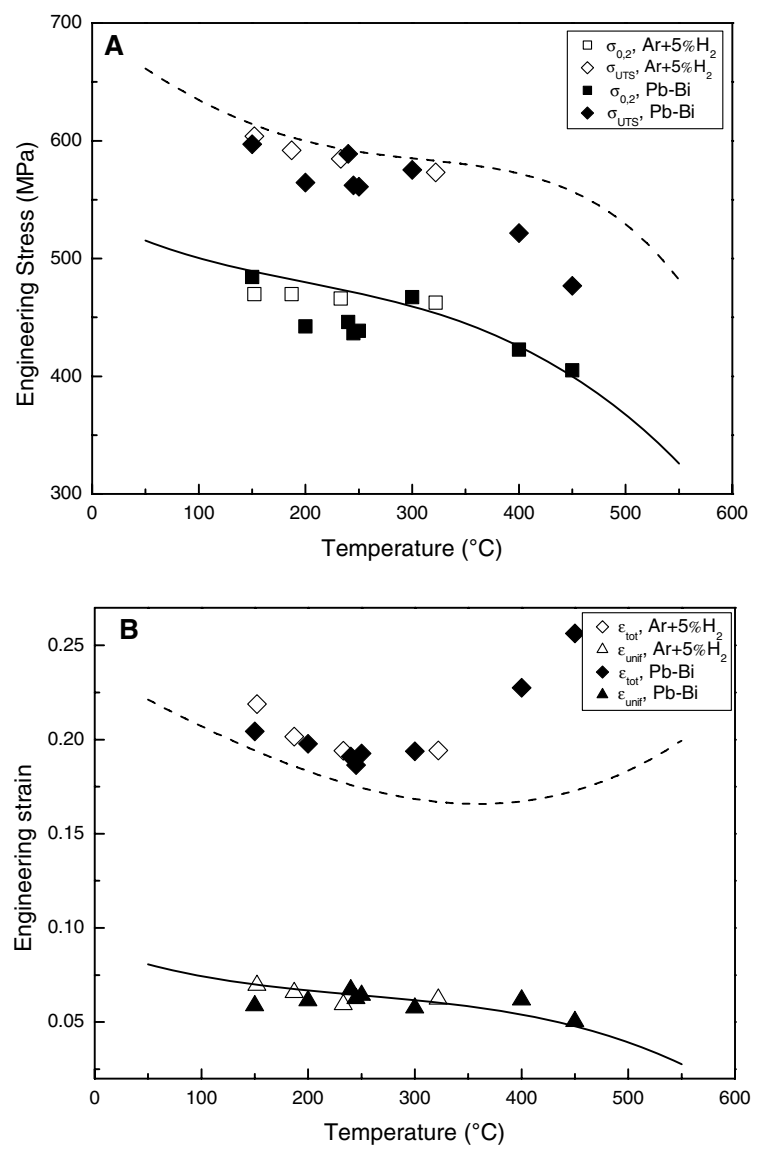

Fig. 3. Tensile results as function of temperature (strain rate: $5 \times 10^{-5} \mathrm{~s}^{-1}$ ). Full symbols for tests performed in LBE, empty symbols for tests performed in controlled gas atmosphere. The lines are obtained from fitting to tensile data from tests in gas environment performed within the Spire project. (A) Influence of temperature on the yield strength and tensile strength; (B) total and uniform elongation as a function of temperature. sile strength, $\sigma_{\mathrm{UTS}}$ are plotted in Fig. 3(A) as function of temperature. At temperatures between 100 and $320{ }^{\circ} \mathrm{C}$ the strength properties of the material are slightly dependent on the test temperature. Above $320^{\circ} \mathrm{C}$ both yield stress and tensile strength decrease. The yield stress of the T91 tested in liquid lead bismuth environment follows the same trend as the reference data. The tensile strength of the T91 tested in LBE above $350{ }^{\circ} \mathrm{C}$ however decreases considerably faster than the reference curve indicates. This might be due to the fact that at temperatures above $300{ }^{\circ} \mathrm{C}$ reference data is scarse and the statistical population for the fitting was insufficiently large.

The results shown in Fig. 3(A) are compatible with the data of Dai et al. [17] obtained using similar slow strain rate tensile tests performed at $300{ }^{\circ} \mathrm{C}$ and at $375^{\circ} \mathrm{C}$ using $5 \mathrm{~mm} \times 1.5 \mathrm{~mm} \times 0.75 \mathrm{~mm}$ rectangular specimens that were electro polished to avoid the presence of sharp microcracks and consequently mechanically polished.

The influence of temperature on the ductility properties plotted in Fig. 3(B) shows that the uniform elongation decreases monotonically with temperature in the interval of $115-450{ }^{\circ} \mathrm{C}$ with values between $7 \%$ and $5 \%$. The environment does not affect the uniform elongation in these conditions and both results from testing in LBE and in gas environments follow the same trend. At temperatures up to $245^{\circ} \mathrm{C}$, the total elongation in both environments decreases with the temperature, reaching a minimum value in liquid metal at $245^{\circ} \mathrm{C}$. The minimum total elongation in the reference curve is at $350{ }^{\circ} \mathrm{C}$. At temperatures above $245^{\circ} \mathrm{C}$ the total elongation in gas environment remains about constant up to $450{ }^{\circ} \mathrm{C}$, whereas in LBE it steadily increases reaching a maximum value at $450{ }^{\circ} \mathrm{C}$. In case of LME one would expect a minimum in the ductility properties at temperatures close to the melting point of lead bismuth eutectic. However, the obtained data clearly demonstrates there is no decrease in mechanical properties when the native oxide layer of the steel has not been removed.

The influence of the strain rate on the mechanical properties of the material was tested using different 
strain rates at a constant temperature. The testing temperatures were $245^{\circ} \mathrm{C}$ and $450{ }^{\circ} \mathrm{C}$ due to the minimum in the total elongation shown in Fig. 3(B) and the fact that the strength properties of T91 decrease above $320{ }^{\circ} \mathrm{C}$.

Tests were performed in liquid metal environment using strain rates between $1 \times 10^{-5} \mathrm{~s}^{-1}$ and $3 \times 10^{-4} \mathrm{~s}^{-1}$ and in controlled gas environment with strain rates between $1 \times 10^{-6}$ and $1 \times 10^{-3} \mathrm{~s}^{-1}$.

Fig. 4(A) shows the strength properties of T91 as function of the strain rate at $245^{\circ} \mathrm{C}$ whereas Fig. 4(B) shows the total elongation and uniform elongation obtained under the same conditions. The full symbols represent data points obtained from tensile tests in liquid metal environment and the empty points represent the results of tests in argon and hydrogen gas environment. The strength
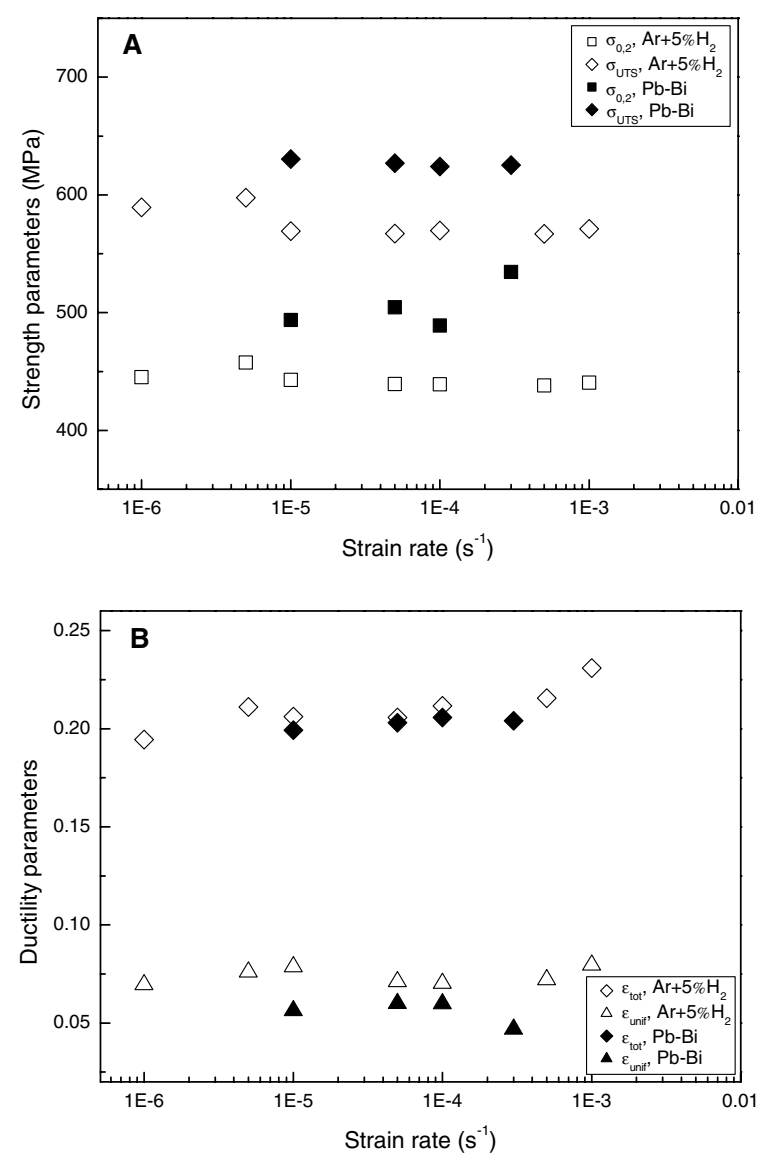

Fig. 4. Tensile results as function of strain rate (temperature: $245^{\circ} \mathrm{C}$ ). Full symbols for tests performed in LBE, empty symbols for tests performed in controlled gas atmosphere. (A) Influence of the strain rate on the yield stress, ultimate tensile strength at $245^{\circ} \mathrm{C}$; (B) influence of the strain rate on the uniform elongation and total elongation at $245^{\circ} \mathrm{C}$. properties are independent of the strain rate both in liquid metal and in gas environment however the values of yield stress and tensile strength are higher in liquid metal environment than in gas when tested at the same strain rate. The ductility properties both in gas and in liquid metal environment are barely influenced by the strain rate at $245^{\circ} \mathrm{C}$. The elongations remain close to the same value although the elongations in the liquid metal environment are little smaller than those in gas environment.

At $450{ }^{\circ} \mathrm{C}$ the tensile tests were only performed in lead bismuth eutectic using strain rates between $1 \times 10^{-6} \mathrm{~s}^{-1}$ and $1 \times 10^{-3} \mathrm{~s}^{-1}$. Fig. 5(A) displays the strength properties of the T91 material tested in LBE at $450^{\circ} \mathrm{C}$ together with reference data obtained from testing in air at $450{ }^{\circ} \mathrm{C}$ [18]. Yield stress and ultimate tensile strength are plotted as a
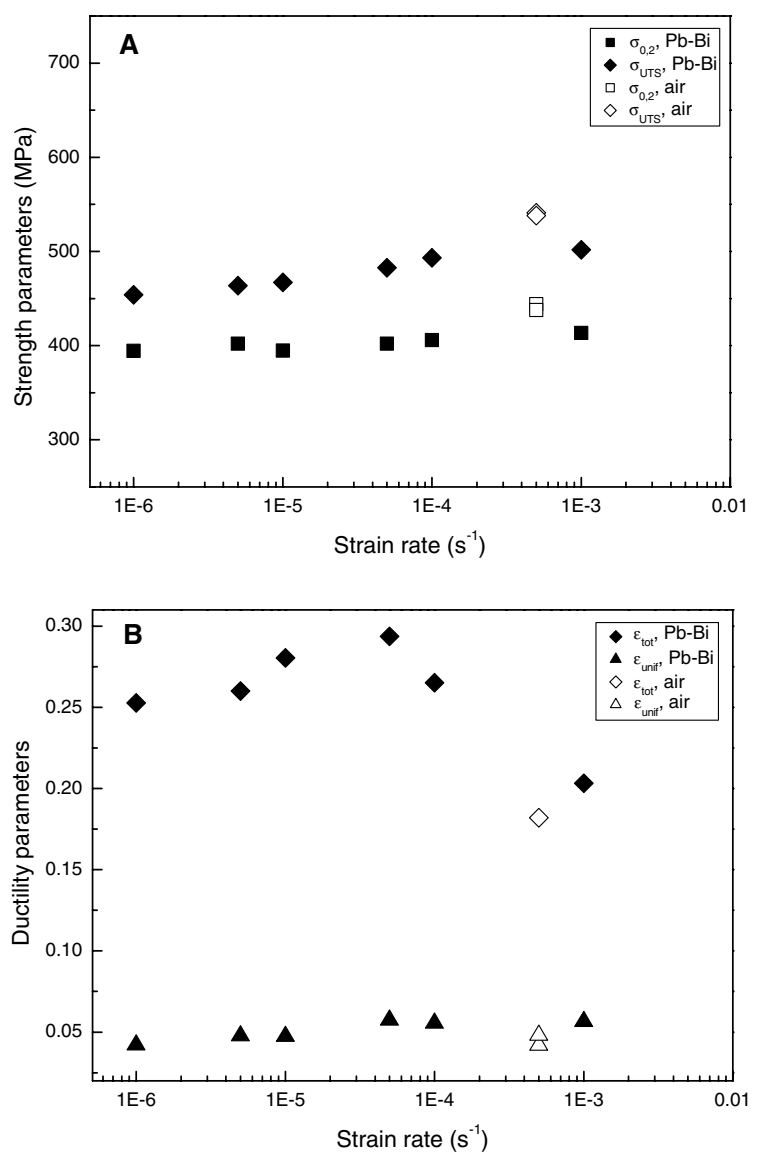

Fig. 5. Tensile results as function of strain rate (temperature $450{ }^{\circ} \mathrm{C}$ ). Full symbols for tests performed in LBE, empty symbols for reference data on the same batch of T91 tested in air. (A) Influence of the strain rate on the yield stress, ultimate tensile strength in $\mathrm{LBE}$ at $450^{\circ} \mathrm{C}$; (B) influence of the strain rate on the uniform elongation and total elongation in LBE at $450{ }^{\circ} \mathrm{C}$. 
function of strain rate. The yield stress remains constant within the observed range of strain rates. However, ultimate tensile strength increases with increasing strain rate. The yield strength and tensile strength of the reference tests performed in air are little higher than those obtained from testing in LBE. Fig. 5(B) shows the total and uniform elongations from the tests in LBE and the total and uniform elongations from the reference tests in air as a function of strain rate. The uniform elongation is not influenced by the strain rate at $450{ }^{\circ} \mathrm{C}$ and remains around 0.05 in all strain conditions. The total elongation exhibits a slight dependence on the strain rate with a maximum between $1 \times 10^{-4}$ and $1 \times 10^{-5}$. No decrease in ductility due to LBE was observed under these test conditions.

Auger et al. [12] has found that under conditions of intimate contact between de-oxidised T91 and LBE there is a clear change in the rupture mode from ductile to brittle when performing classical tensile tests even in uncontrolled LBE environment. However, in the work presented here there was no deterioration in ductility or strength of the T91 material tested in the controlled chemistry (low O-concentration) liquid lead bismuth as compared to the tests under controlled gas environment. This apparent contradiction might be explained by two possibilities: either there was insufficient wetting during these tests and/or the absence of localised corrosion (initiated cracks) at our specimen surfaces. The latter has been confirmed by the microscopical examinations of the specimen surfaces before and after the tests which reveal the absence or at least non-observable localised LBE penetration on the specimens even at $450{ }^{\circ} \mathrm{C}$. It is due to the fact that the test duration is relatively short and the samples were not pre-treated to remove the native oxide layer. Regarding the wetting, as the oxide layer is much harder and thus less ductile than the underlying base metal, it is assumed that the oxide layer at the surface breaks under the applied stress so revealing the underlying metal and allowing intimate contact between the liquid lead bismuth and the base metal. So, local wetting of bare surface of the tested steel was indeed possible, unless T91 (high Cr steel) would have the necessary time to repassivate in an oxide poor environment. This means that the bare base metal uses oxides present in the liquid metal environment to form a new oxide layer on its surface. Due to this repassivation of the surface high chromium steels are said to have a self healing oxide layer. These two surface mechanisms of breaking under stress and repassivation are clearly competing and the relative speed of the two determines the degree of wetting. As we have no data on the actual kinetics of these two phenomena, it is difficult to state if the material was partially wetted or not. However, we believe that the environmental embrittlement of T91 due to the presence of LBE is possible only in the case of the presence of an initial crack having a certain critical length, wetted at the atomic scale and having a plastic deformation at its tip. It is therefore reasonable that we did not see LME in these experiments due to the fact that there was no local corrosion attack during the test that would allow the initiation of the above described crack. Further, it might be considered that the self healing mechanism of the material was also fast enough to repassivate the layer under the tested conditions.

A further study was therefore conducted by preexposing tensile samples of untreated T91 in LBE with low oxygen concentration at $450{ }^{\circ} \mathrm{C}$ for $4000 \mathrm{~h}$ prior to tensile testing at a strain rate of $5 \times 10^{-5} \mathrm{~s}^{-1}$ at temperatures of $300{ }^{\circ} \mathrm{C}$ and $450{ }^{\circ} \mathrm{C}$. The tensile curves were compared to ones obtained from testing non-exposed T91 material under the same conditions. The curves are shown in Fig. 6 . The T91 showed a decrease in total elongation while yield strength and tensile strength remained constant when tested in lead bismuth environment at $450{ }^{\circ} \mathrm{C}$. However, the sample tested in LBE at $300{ }^{\circ} \mathrm{C}$ did not show any significant sign of decrease in tensile properties after being pre-exposed for

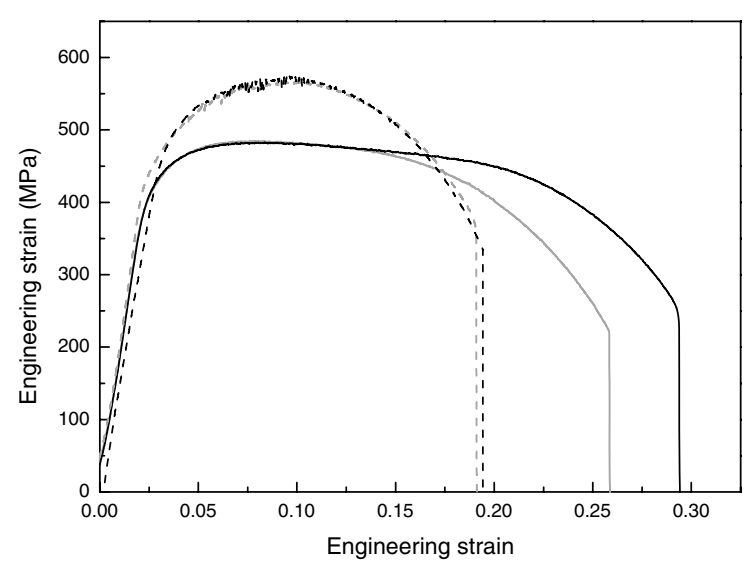

Fig. 6. Tensile curves from tests at $300{ }^{\circ} \mathrm{C}$ (dashed) and $450{ }^{\circ} \mathrm{C}$ (solid) for samples of $\mathrm{T} 91$ that were pre-exposed to $\mathrm{Pb}-\mathrm{Bi}$ at $450{ }^{\circ} \mathrm{C}$ for $4000 \mathrm{~h}$ (gray curves). The black curves result from tensile testing T91 without pre-exposure to $\mathrm{Pb}-\mathrm{Bi}$ under the same conditions. 


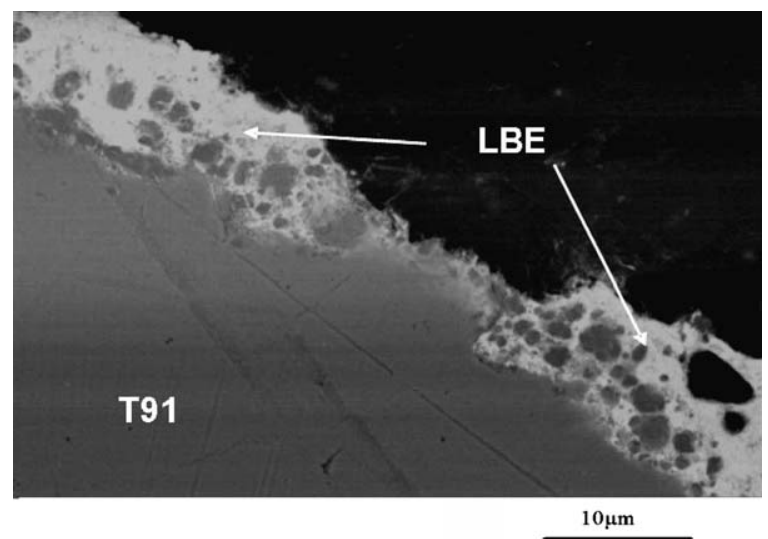

Fig. 7. SEM observation of the surface layer of the T91 sample, tested at $450{ }^{\circ} \mathrm{C}$ after $4000 \mathrm{~h}$ of exposure in oxygen poor LBE. Locally the oxide layer can no longer be clearly distinguished and shows penetration of LBE.

$4000 \mathrm{~h}$ at $450{ }^{\circ} \mathrm{C}$ under the same conditions as the sample tested at $450{ }^{\circ} \mathrm{C}$. SEM observations of the corrosion at the surface of the samples determined that the sample tested at $300{ }^{\circ} \mathrm{C}$ still had an almost uniform oxide layer on its surface whereas the sample tested at $450{ }^{\circ} \mathrm{C}$ showed small local penetrations of the LBE (Fig. 7). The fracture surface of the preexposed sample tested at $450{ }^{\circ} \mathrm{C}$ is shown in Fig. 8 and consists of two different types of fracture surface. The majority of the fracture surface is dimpled (Fig. 8(A)) but on one side it has a more brittle appearance (Fig. 8(B)). Based on the fracture surface of the sample tested at $450{ }^{\circ} \mathrm{C}$ and the observations of its corroded surface, it is thought that the penetration of LBE created a surface defect similar to a crack. When the stress reaches a value above the tensile strength, preferential deformation will occur at the section of the surface defect provided that the defect or crack is sufficiently large. As the liquid metal is known to lower the surface tension of the newly formed fracture surface, its presence is likely to increase the propagation speed of the fracture thus lowering total elongations. The physical reason for the transition of fracture mode which can be seen on the SEM observation of the fracture surface in Fig. 8 is unclear at this time. Other work showing a transition of fracture mode in an LME study [12] has proposed that the insufficient supply of LBE to the crack tip led to the transition in fracture mode. This is unlikely to be the reason since the sample was submerged in 21 of LBE and the crack is further opened as the test continues.

To strengthen this theory of increased crack propagation due to the presence of LBE, tensile tests were performed on notched specimens at $200{ }^{\circ} \mathrm{C}$ in lead bismuth and in argon and 5\% hydrogen atmosphere.

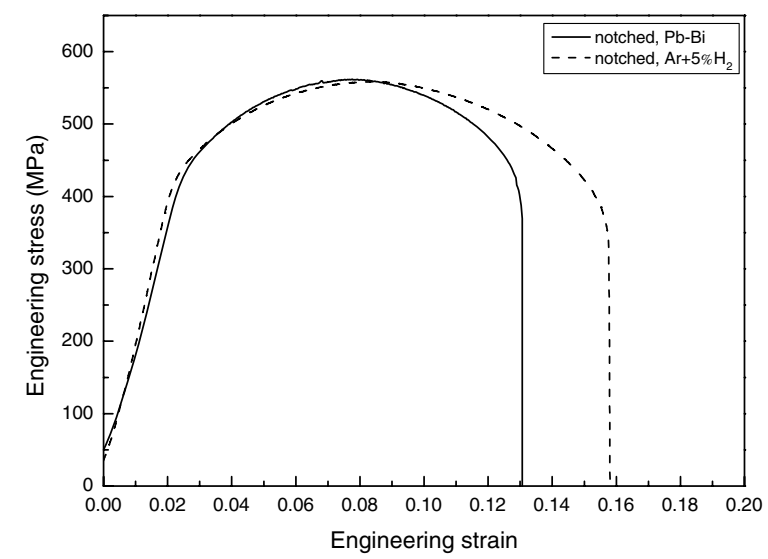

Fig. 9. Tensile curves from tests at $200^{\circ} \mathrm{C}$ using notched samples at $5 \times 10^{-5} \mathrm{~s}^{-1}$. Dashed curve resulted from testing in $\mathrm{Ar}+$ $5 \% \mathrm{H}_{2}$, the solid curve from the test in LBE.

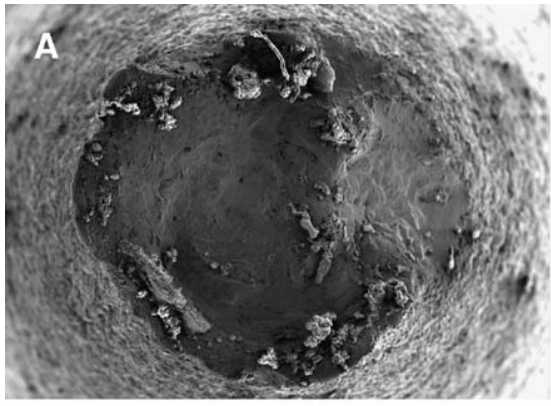

$100 \mu \mathrm{m}$

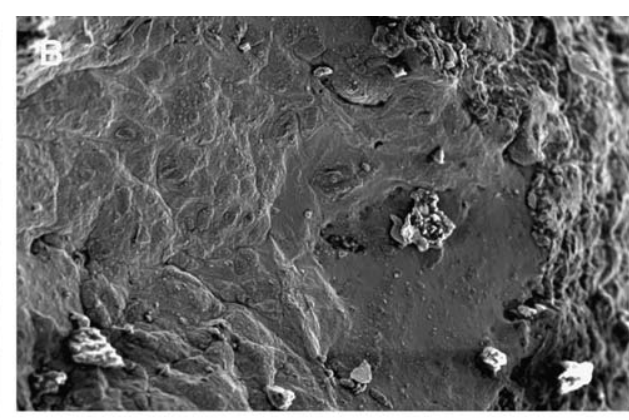

$100 \mu \mathrm{m}$

Fig. 8. SEM observation of the fracture surface of the pre-exposed T91 sample tested at $450{ }^{\circ} \mathrm{C}$. (A) Overview of the entire fracture surface showing two different types of roughness; (B) the brittle part of the fracture showing steps due to the actuator of the stepmotor. 

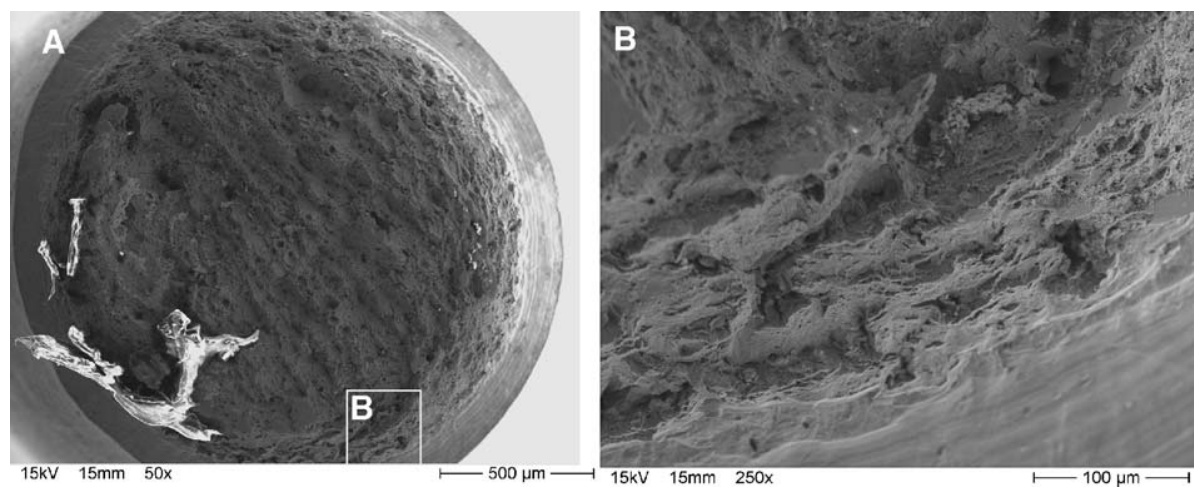

Fig. 10. SEM observation of the fracture surface of the notched T91 sample tested in $\mathrm{LBE}$ at $200{ }^{\circ} \mathrm{C}$. (A) Overview of the entire fracture surface. The brighter parts in the picture are pieces of LBE that were not removed by the cleaning of the sample; (B) close up of the edge of the sample showing the rim of the machined notch. The edge of the sample shows a partly brittle fracture surface.

The notches had a depth of $0.1 \mathrm{~mm}$ with an opening angle of $60^{\circ}$.

The obtained tensile curves are shown in Fig. 9. It can be seen that the total elongation was reduced while the yield strength and tensile strength remain the same when testing a notched sample in LBE compared to a similar test in $\mathrm{Ar}+5 \% \mathrm{H}_{2}$. The SEM observation of the fracture surface of the notched sample tested in LBE is shown in Fig. 10. Fig. 10(A) shows the overview of the fracture surface. The majority of the surface was ductile clearly showing dimples. On the edge of the fracture surface however, areas that were not fully ductile, showing some faces could be distinguished as can be seen in Fig. 10(B).

It is clear that the native oxide layer present on the T91 steel protects the material from any LME effect. The untreated T91 does not undergo a decrease of mechanical properties under any of the conditions of temperature and strain rate. When a crack of sufficient magnitude caused by machining or by liquid metal corrosion is present however the propagation speed of the fracture is increased by the presence of LBE. This results in a decrease of the total elongation while values of yield strength and tensile strength remain the same.

\section{Conclusions}

The susceptibility of the ferritic-martensitic steel T91 to liquid metal embrittlement was examined in the temperature range between $150^{\circ} \mathrm{C}$ and $450^{\circ} \mathrm{C}$, using strain rates between $1 \times 10^{-3}$ and $1 \times 10^{-6}$. The objective was to study whether or not the susceptibility to LME or the absence of LME is influenced by the temperature or the applied strain rate. Except for the total elongation the mechanical parameters are identical in both environments and no embrittlement or decrease in mechanical properties by liquid lead bismuth was observed. Varying the strain rate does not have an influence on the susceptibility to LME of the untreated T91 material. At temperatures above $300{ }^{\circ} \mathrm{C}$ the total elongation of the untreated T91 is greater in liquid metal than that in gas environment when comparing to reference data from the same batch of T91. However in case a sufficiently large surface defect such as a local corrosion attack or a notch is present, the total elongation is reduced when tested in LBE while the yield strength and tensile strength remain the same.

\section{References}

[1] C. Rubbia, J.A. Rubio, S. Buono, F. Carmianti, N. Fietier, J. Galvez, C. Geles, Y. Kadi, R. Klapish, P. Mandrillioni, J.P. Revol, C. Roche, CERN Report AT/95-44 (ET), 1995.

[2] H.U. Knebel, X. Cheng, C.H. Lefhalm, G. Müller, G. Schumacher, J. Konys, H. Glasbrenner, Nucl. Eng. Des. 202 (2000) 279.

[3] H. Aït Abderrahim, P. Kupschus, E. Malambu, Ph. Benoit, K. Van Tichelen, B. Arien, F. Vermeersch, P. D'hondt, Y. Jongen, S. Ternier, D. Vandeplassche, Nucl. Instrum. and Meth. A 463 (2001) 487.

[4] W. Rostoker, J.M. McCoughy, M. Markus, in: Embrittlement by Liquid Metals, Reinhold, Chapman and Hall, New York, London, UK, 1960.

[5] M.H. Kamdar, Prog. Mater. Sci. 15 (4) (1973) 289.

[6] B. Joseph, M. Picat, F. Barbier, Eur. Phys. J. AP 5 (1999) 19.

[7] C.F. Old, J. Nucl. Mater. 92 (1980) 2.

[8] A.R.C. Westwood, C.M. Preece, M.H. KamdarAdsorption Induced Brittle Fracture in Liquid Environments, 3, Academic Press, 1971, p. 589.

[9] V.V. Popovich, I.G. Dmukhovskaya, Sov. Mater. Sci. 365 (1978) 
[10] H. Glasbrenner, F. Gröschel, J. Nucl. Mater. 335 (2004) 239.

[11] FP6-EUROpean Research Programme for the TRANSmutation of High Level Nuclear Waste in an Accelerator Driven System, Contract no. FI6W-CT-2004-516520 (www. eurotrans.de).

[12] T. Auger, G. Lorang, S. Guerin, J.-L. Pastol, D. Gorse, J. Nucl. Mater. 335 (2004) 227.

[13] G. Nicaise, A. Legris, J.B. Vogt, J. Foct, J. Nucl. Mater. 296 (2001) 256

[14] S. Guerin, J.-L. Pastol, C. Leroux, D. Gorse, J. Nucl. Mater. 318 (2003) 339.

[15] A. Aiello, M. Agostini, G. Benamati, B. Long, G. Scaddozzo, J. Nucl. Mater. 335 (2004) 217.

[16] D. Sapundjiev, A. Almazouzi, S. Van Dyck, J. Nucl. Mater., these Proceedings, doi:10.1016/j.jnucmat.2006.05.030.
[17] Y. Dai, B. Long, F. Groeschel, J. Nucl. Mater., these Proceedings, doi:10.1016/j.jnucmat.2006.05.039.

[18] J.B.J. Hegeman, J. Rensman, Window Materials for ADS, NRG deliverable 16 part 1: Contract no. FIKW-CT-200000058.

[19] E. Lucon, A. Almazouzi, Scientific Report SCK.CEN-BLG973, Feb'2004.

[20] Y. de Carlan, S. Urvoy, Y. Tournie, P. Wident, Technical document DMN/SRMA/LA2M/NT/2004-2581/A.

[21] M. Matijasevic, D.E.A. Métallurgie et Matériaux-Rapport de Stage, Institut National des Sciences et Techniques Nucléaires de Paris, Soutenance: 23/06/2003.

[22] Y. Dai, X. Jia, R. Thermer, F. Groeschel, FP5 Euratom Framework Programme, 1998-2002, Deliverable no 47, Month 48, Contract no. FIKW-CT-2000-00058. 